\title{
DOES UNDERNUTRITION DURING INFANCY INHIBIT BRAIN GROWTH AND SUBSEQUENT INTELLECTUAL DEVELOPMENT?
}

\author{
BY \\ M. B. STOCH and P. M. SMYTHE \\ From the Department of Child Health, Red Cross War Memorial Children's Hospital and University of Cape Town, \\ South Africa
}

(RECEIVED FOR PUBLICATION MAY 10, 1963)

Experiments at Cambridge have shown that undernutrition during the early period of growth of calves will result in a reduction in size of the mature animal even if a high level of feeding is subsequently given, whereas a similar period of undernutrition in the 2-year-old animal, which was well fed as a calf, has much less effect on the mature size (Brookes and Vincett, 1950). The slower maturing zebu (Bos indicus) variety of cattle, which is bred in South Africa, appears to be less affected in their mature size by undernutrition when calves. These findings justify making a fairly obvious hypothesis that undernutrition may influence the mature size of an animal according to the age at which it occurs - the greatest effect being at the period of maximum growth-and by its duration relative to the total period of growth.

When applied to human nutrition, this concept suggests that undernutrition during infancy might result in some reduction in the adult body size, but seeing that growth continues for 18 years, providing subsequent nutrition is good, the effect should be limited. There is, however, a notable exception, that is the brain. The first two years of life are not only the period of maximum growth $-70 \%$ of the adult brain weight is reached by the end of the first year-but also they constitute almost the entire period of brain growth (Fig. 1). The interesting possibility arises that undernutrition during infancy may result in failure of the brain to achieve its full potential in size, and it is not unreasonable to suppose that this may also predispose to inhibition of optimum intellectual and personality development.

To test this hypothesis, a group of infants was selected who, solely due to undernutrition, were grossly underweight when they were first seen. They were matched with an adequately nourished control group from an approximately similar socio-economic background. A comparative longitudinal study of head circumference, and physical and intellectual development of the two groups is reported. It was not possible to assess personalities of the mothers and children.

\section{Method}

Over a period of five years, two groups, each of 21 Cape Coloured children, were collected. Eighteen of each group were between the ages of 10 months and 2 years, the remaining three between 2 and 3 years. They were followed up for periods of from two to seven years, from June 1955 to March 1962. Initially, none of the children showed clinical evidence of organic disease apart from gastro-enteritis, and this responded to treatment. Their chest radiographs, Mantoux tests and Wassermann reactions were all negative. The essential difference between the two groups was in their state of nutrition.

The undernourished group consisted of 11 girls and 10 boys. When first seen, the mean weight of 14 of them who were between the ages of 10 and 16 months was $11 \mathrm{lb} .8 \mathrm{oz}$. $(5 \cdot 21 \mathrm{~kg}$.); the remainder weighed less than $18 \mathrm{lb} .(8 \cdot 16 \mathrm{~kg}$.). All the children fell well below the 2.5 percentile of the average weight for Cape Coloured children of their age (Robertson, 1961).

The children in the control group were matched with the undernourished children on a basis of age and sex. They attended an all-day nursery-cum-crèche, while both parents were in full employment. At the crèche they received adequate meals and vitamin supplements. The average weight of this group at 1 year of age was $18 \mathrm{lb} .(8 \cdot 16 \mathrm{~kg}$.), with a range of $15 \mathrm{lb} .10 \mathrm{oz} .(7 \cdot 08 \mathrm{~kg}$.) to $20 \mathrm{lb} .14 \mathrm{oz}$. $(9.46 \mathrm{~kg}$.). Their mean weight fell at the 10th percentile of the average weight of Cape Coloured children of this age.

The undernourished children were examined originally at about 1 year of age and subsequently at six- to 12-monthly intervals. An attempt was made to see each matched control child at the corresponding age.

At each examination, height, weight and head circumference were measured. It has been assumed that head 


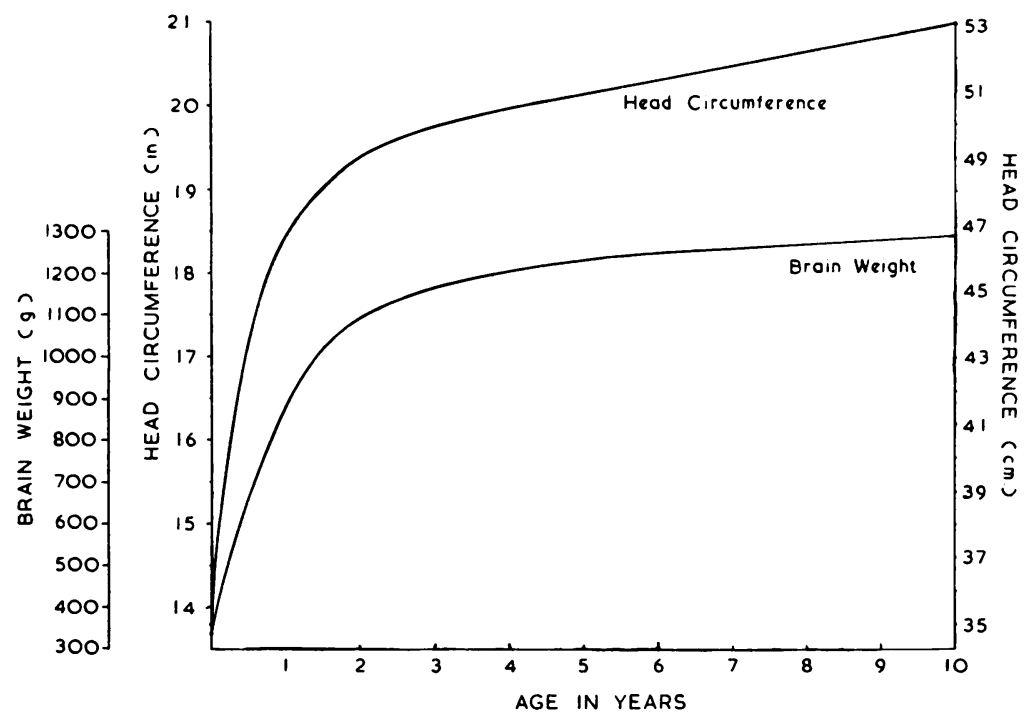

FIG. 1.-The rate of increase of head circumference (Holt and McIntosh, 1953) and brain weight (Coppoletta and Wolbach, 1933) of normal children. It can be seen that the relative rates of increase are fairly similar. Nearly all growth of the brain occurs in the first two years; by the age of 4 it virtually ceases.

circumference reflects fairly accurately the brain size. A small error will result since from the shape of the curves in Fig. 1 it can be seen that after the age of 4 years when brain growth practically ceases head circumference continues to enlarge because of growth in thickness of the scalp and skull. This, however, should not affect the comparative sizes of the heads of children of the same age.

Up to the age of 2 years, the intelligence quotient (I.Q.) was estimated using Gesell and Amatruda's Infant Scales of Mental Development (1947). From 2 to 6 years the Merrill-Palmer Test was used (Stutsman, 1948). This test, translated into Afrikaans, has been found to be the most suitable for use among Cape Coloured pre-school children (Grover, 1952; Botha, 1952). After the age of 6 years, the Individual Scale of the National Bureau of Education Research of South Africa (Fick, 1939), which is based on the 1916 Stanford Revision of the Binet-Simon Intelligence Scale, was used.

The head circumference of the parents of both groups was measured. Their intellectual capacity was also assessed using Raven's Standard Progressive Matrices (Raven, 1956). Raven's Matrices which has a general intelligence factor (' $\mathrm{g}$ ') saturation of 0.82 was selected because it provides an index of intellectual capacity whatever the nationality, education or literacy of the individual. The socio-economic and educational status of each family was noted.

\section{Results}

In all the graphs the measurements of boys and girls have been combined, because the only available standards for comparison with the Cape Coloured children under 6 years do not distinguish between the sexes.

Head Circumferences. In Fig. 2 the average head circumferences of boys and girls of the undernourished group and the control group are compared with the mean for American children (Holt and McIntosh, 1953), as no figures are available for Cape Coloured children. At all ages the undernourished group falls below the control group, which compares favourably with American children. When last measured, the difference of the means of 0.90 in. $(2.28 \mathrm{~cm}$. $)$ was statistically significant $(\mathrm{t}=4 \cdot 52, \mathrm{p}<0 \cdot 01)$.

Intelligence Quotients. In Fig. 3 are plotted the intelligence quotients of the two groups of children. It can be seen that at all ages the mean of the undernourished group is well below the control group and that the difference between the means remains relatively constant. At the final testing the mean I.Q. of the undernourished group $(70 \cdot 86)$ differs from that of the control group $(93.48)$ by 22.62 points. This is statistically significant $(t=7 \cdot 6$, $\mathrm{p}<0.01)$.

Weights. In Fig. 4 is shown the average weight of boys and girls of the undernourished group, the control group and the 50th percentile for Cape Coloured children at the various age levels. The 


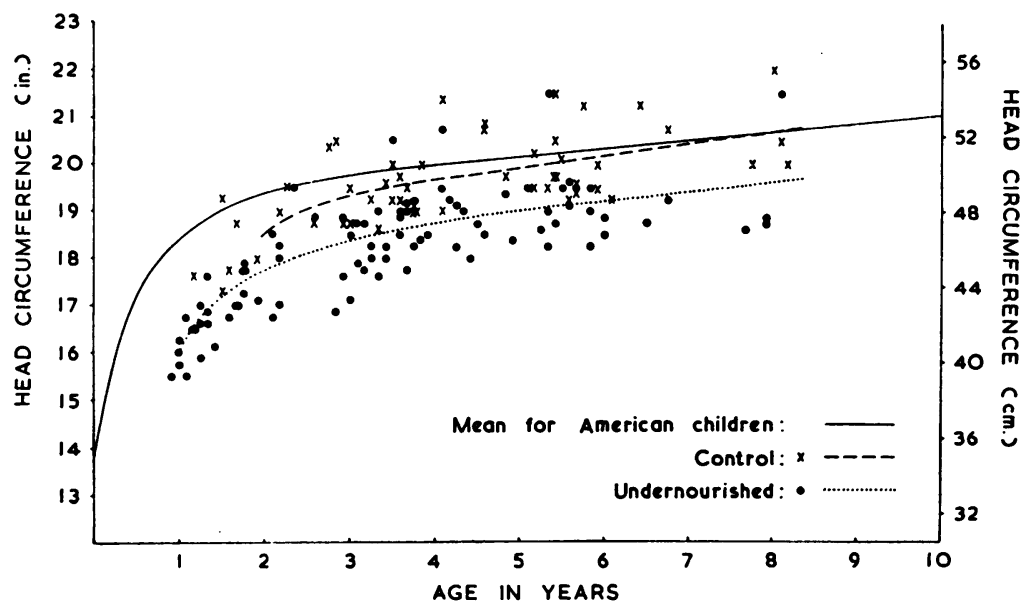

Fig. 2.-Comparison of the mean head circumference for boys and girls of the undernourished and the control group with the mean for American children.

marked difference between the mean weights of the undernourished and control groups at the start of the trial can be seen to be lessening as the children grow older. At the final weighing the difference between the mean weights of the two groups is $5 \cdot 23 \mathrm{lb} .(2 \cdot 35 \mathrm{~kg}$.). This is statistically significant $(t=2.44, p<0.05>0.01)$. The extent of this difference is partly accounted for by some of the children still being in the lower age-groups.

Heights. In Fig. 5 are represented the average heights of boys and girls in the undernourished group and the control group. At all ages the under- nourished group falls below the control group. The difference of 3.48 in. $(8.8 \mathrm{~cm}$.) between the mean heights of the two groups at the final testing is statistically significant $(\mathrm{t}=2 \cdot 85, \mathrm{p}<0 \cdot 01)$.

The Intelligence Quotients and Head Circumferences of Parents. Difficulty was experienced in comparing the I.Q.s of the parents because Raven's Tables are partly determined by age and do not provide percentiles for dull people over the age of 30 . The mean I.Q. of all parents was found to be very low and a number fell into this untabulated category. For this reason, all scores at or below the 25th

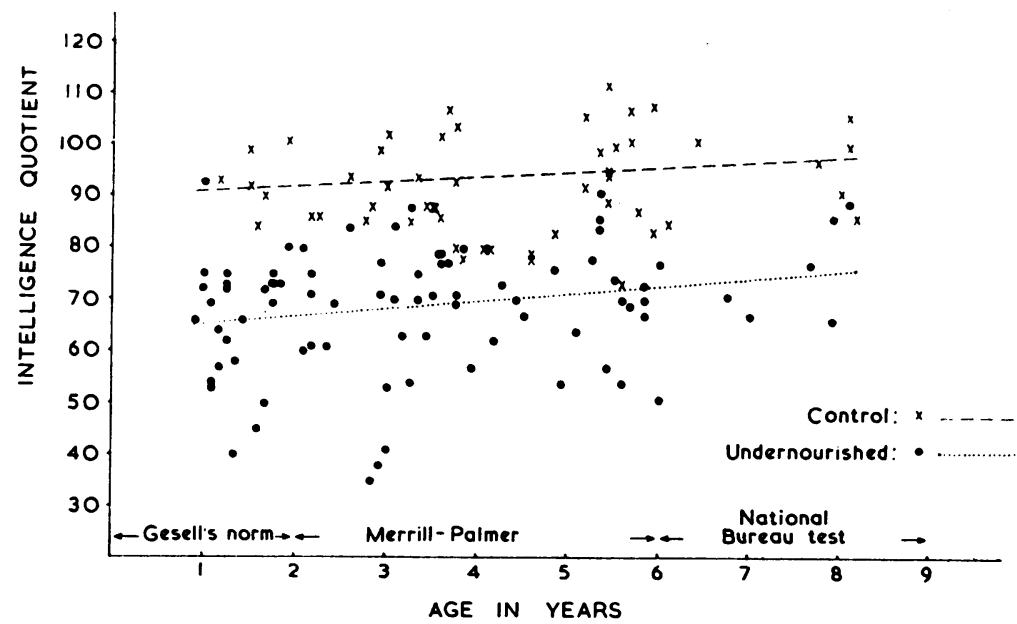

FIG. 3.-Comparison of the mean I.Q. of the undernourished group with the mean I.Q. of the control group. 


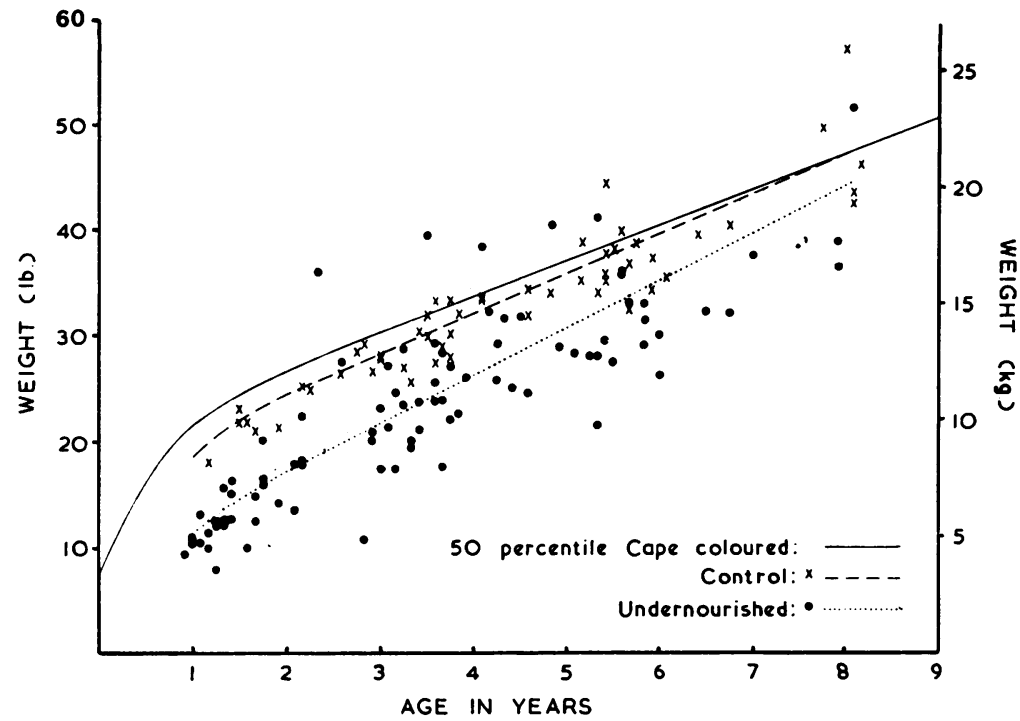

Fig. 4.-Comparison of the mean weights of boys and girls of the undernourished group, the control group and the 50th percentile for Cape Coloured Children.

percentile were given a percentile rank of 25 . On this basis there is no statistical difference between the two groups. As a further check the raw scores of the two groups have been compared and this, too, is not significantly different (Table).

The mean head circumference of the parents of the undernourished group was $21 \cdot 64$ in. $(54 \cdot 8 \mathrm{~cm}$.) (S.D. 0.77 ) and of the control group $21 \cdot 83$ in.
(55 cm.) (S.D. 1·11). The difference is not significant $(t=0.83, p=0.4)$.

Socio-economic Factors. The undernourished group originally consisted of 24 children; three died of marasmus and gastro-enteritis. They lived under atrocious conditions in lean-to, corrugated iron, one-room shanties built on sand in various slum

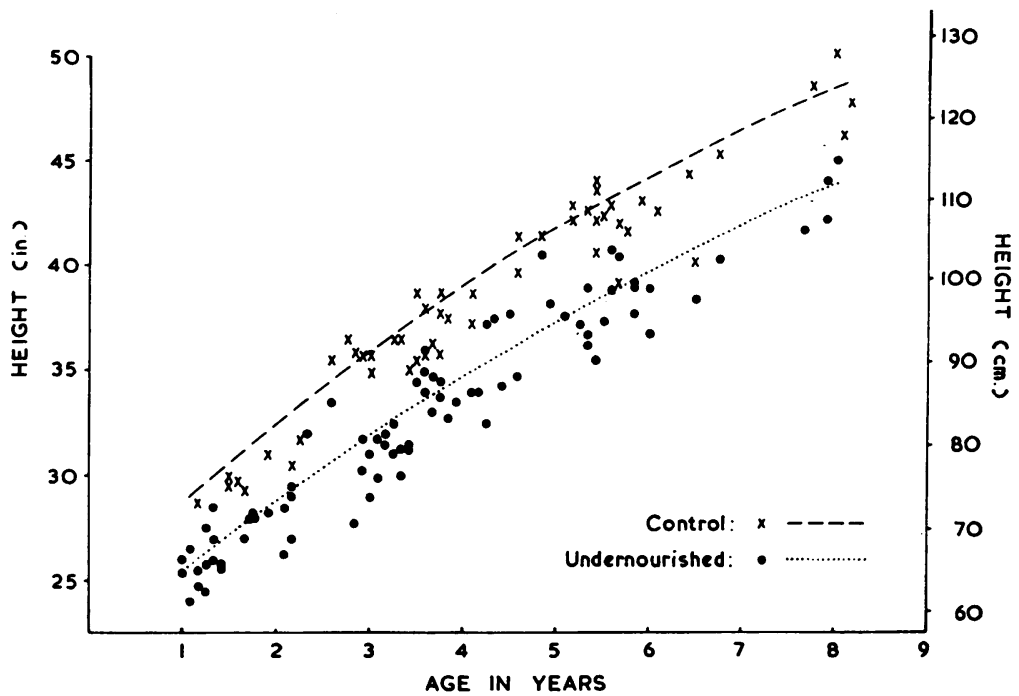

FIG. 5.-Comparison of the mean heights of boys and girls in the undernourished group with the control group. 
TABLE

ANALYSIS OF THE I.Q.S OF THE PARENTS

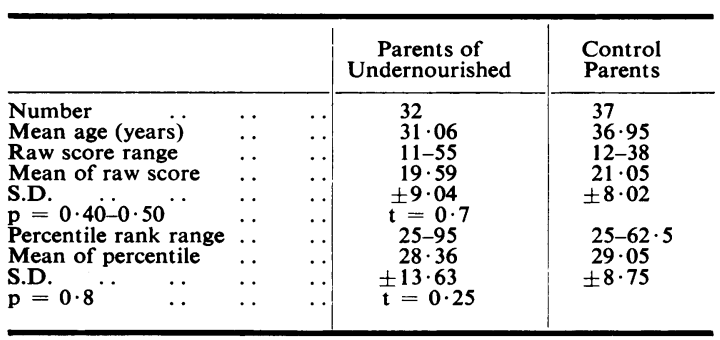

areas without any sanitary facilities. Those who lived in houses were crowded into unventilated dark back rooms. Thirteen $(62 \%)$ were illegitimate and in a further three $(14 \%)$ cases the fathers had absconded. Only three of the fathers were in regular employment. The mothers appeared lazy and too apathetic to care for the well-being of their children. Though the social workers and district nurses repeatedly requested the mothers to take the children daily to Municipal soup kitchens or Clinics for meals, there was very little co-operation.

The families of the control group all lived in a Municipal housing scheme consisting of two- or three-roomed brick houses with kitchens, bathrooms and water sanitation. They were all neatly maintained and well furnished. All the fathers and mothers were employed. One father $(5 \%)$ was separated from his family but still helped to support them. All the children were legitimate.

A comparison was made of the educational and economic backgrounds of the two groups. With the control group placed in brackets, the average number of children per family was $3.7(5 \cdot 7)$, and the mean weekly income was $£ 3$ ss. $4 \mathrm{~d}$. ( $£ 513 \mathrm{~s}$. 4d.). Five of the undernourished families had no source of income. The average level of education attained by the parents was Standard $3 \cdot 3(4 \cdot 4)$, with four (two) parents illiterate. The number in skilled occupations was one (two). The control children tended to come from larger families with larger incomes and less unemployment and their parents had slightly higher educational attainments. Both groups fell within the lowest economic group of unskilled labourers with minimal incomes.

\section{Discussion}

The children of this study are still too far from maturity for it to be suggested that the original hypothesis has been proved. Although the followup continues, it may be that no final answer will be obtained as to whether brain growth is more affected than body growth since it has not been possible to fulfil one of the postulates, that equal and adequate nutrition should be maintained in all cases subsequent to the period of undernutrition. Some idea of the relative rates of growth can be obtained by a comparison of progressive matrices of the undernourished and control groups. The difference in height has persisted, although the mean difference in weight between the two groups is becoming less. The difference in head circumference has remained constant. In the older children this difference is likely to be permanent as little further growth in head circumference occurs after the age of 10 . If the assumption that head circumference reflects brain mass is justified, it means that there has been significantly less brain growth. In the same group the mean I.Q. was significantly lower. In normal people there is no correlation between head circumference and I.Q. This does not, however, exclude the possibility of suboptimal brain growth due to malnutrition being associated with a failure to achieve the full potential in I.Q. This could explain the findings in this study. It should be stressed that the control group was drawn from the lowest educational and economic group of the Cape Coloured people. The mean I.Q. of 92.5 compares well with the mean I.Q. of 93.8 of the children from the lowest socio-economic and parental educational levels in the United States of America (McNemar, 1942).

Many factors are known to influence the intelligence of a child. The effect of heredity must be the most difficult to evaluate, but, as far as could be determined, the intelligence of the parents of each of the groups was comparable. Of the other factors, emphasis must be laid on the physical immobility and listlessness of some of these undernourished infants. When first seen many of them seemed to move only their eyes. Furthermore, they had probably been in this state for some time. The effect of psychological factors such as maternal neglect and emotional deprivation on intellectual development was impossible to assess in this study. This is a significant factor that cannot be excluded.

Another factor is the effect of attendance at a nursery school which tends to increase the I.Q. of children by about five or six points (Wellman, 1945). This is not enough, however, to account for the mean difference between the two groups of 22.6 I.Q. points, which was found at the final examination. The occupation and education of parents are known to influence the I.Q. of their children (Bayley and Jones, 1937). On educational levels the parents were fairly evenly matched. The most likely factor to account for the difference in intelligence appears to be the state of their nutrition during infancy. 
Paton and Findlay (1926) concluded that the state of nutrition of the child was more closely related to the mother's efficiency than to poverty, underfeeding and overcrowding. The level of maternal efficiency can only be the more important factor above a certain level of poverty, below which, however efficient the mother may be, nutrition must suffer. In this investigation the efficiency of the mother in caring for her child was an important point of difference in the environment of the two groups of children. The mothers of the undernourished children were more inclined to be negligent, apathetic and irresponsible. This was shown by the high illegitimacy rate, the persistent failure to take advantage of welfare facilities and the high mortality rate of their children.

A number of criticisms can be directed at this study. There is the possibility of some organic brain disease being present in the undernourished infants. These children differed from those in whom a small head circumference and cortical atrophy were associated with failure to thrive (Smythe and Bouchier, 1960) in that they rapidly gained weight on receiving a hospital diet, and none of them showed any clinical evidence of disease of the central nervous system. It seemed justifiable to do air encephalograms to exclude cortical atrophy, but when the first two cases were found to be normal, no further studies were made. It could be that, in selecting infants of abnormally low weight, a number of congenital microcephalics were included. Had this been so, it is surprising how constant was the subsequent finding of a background of nutritional neglect. The original selection was made solely on a weight basis, without any knowledge of the environment.

Prematurity does not appear to have been a significant factor. One infant was in a hospital premature unit. Two others were stated to have weighed just under $5 \mathrm{lb}$. $(2 \cdot 26 \mathrm{~kg}$.) at birth. Birth weights were not available for two infants; but there was no suggestion from the mothers that they were smaller than average, and the chances of prematures surviving under the home conditions of the undernourished group must have been small.

The question of bias also arises when the tester is personally aware and interested in the outcome of the tests. Ideally, this investigation should have been conducted along the lines of a 'blind' study, but for practical purposes this was impossible. It was felt that all the children had to be tested by the same examiner and this made it even less practical to obtain the services of a disinterested person.

An error arising from the original selection of the children seems the more likely cause of reaching an erroneous conclusion than is bias in the observations. Grossly underweight infants were deliberately selected because it was thought that, with so many factors that might affect intelligence, only by comparing extreme degrees of undernutrition could an answer be obtained.

Reviews of the literature on the relation between undernutrition and intellectual development make no reference to children under 2 years of age. Kugelmass, Poull and Samuel (1944) studied groups of undernourished children who were over 2 years: 2 they found that improvement in diet was followed by an improvement in the I.Q. of undernourished normal children by 18 points. Their finding that the earlier the age at which nutritional therapy was instituted the better the rise in the I.Q., and that after the age of 4 the rise was insignificant, has implications that are in keeping with the findings of this series. A conclusion generally expressed has been that children of superior or good average intelligence can withstand severe and prolonged undernutrition without intellectual impairment. Emphasis has been laid on the effect of lessened energy, inability to concentrate and early fatigue due to malnutrition on intellectual accomplishments. A similar effect on children of lower intelligence may cause them to appear subnormal, but as soon as the underfeeding is corrected the children rapidly make up lost ground. Only with excessively severe and prolonged malnutrition can the astonishing powers of resistance of the central nervous system be overcome and permanent intellectual damage result (Tredgold, 1956; Blanton, 1919).

It may well be that the children of this series fall into this category of very severe undernutrition, and that had there been only a small improvement in their diet, intellectual impairment might have been prevented. Nevertheless, the main contention here presented, that it is undernutrition during infancy (which is the period of almost the entire growth of $L$ the brain) that is most likely to have a permanent inhibiting effect, does not appear to have been studied previously in man.

Recently McCance (1962) has stressed the importance of the time and the duration of malnutrition on growth in animals. Jackson and Stewart (1920) found that the weight of the brain and nervous system of rats was subnormal if stunting of growth due to undernutrition was severe and begun at an early age. Cowley and Griesel $(1959,1962)$ have found that the first filial generation born of rats maintained on a low protein diet have a lowered learning ability, and that both prenatal and postnatal nutritional factors may play a part. While 
these findings are relevant, some hesitancy is justified in comparing the results of experiments on lower animals with humans especially in regard to functioning of the central nervous system.

In conclusion, although these findings do not provide proof they are certainly suggestive that severe and prolonged undernutrition during infancy can permanently retard brain growth and intellectual development and, if confirmed, they add much emphasis and urgency to the need for good nutrition at this age.

\section{Summary}

Nutritional experiments on calves suggest that the effect of undernutrition on mature size is most marked if it occurs during the period of maximum growth, and also according to its duration relative to the total period of growth. When applied to human nutrition, this concept suggested that undernutrition during infancy might have its greatest effect on growth of the brain. Retardation of intellectual capacity is a likely consequence. This study, in which a group of Cape Coloured children who were grossly undernourished during the first year of life was compared with a matched control group, supports this hypothesis. Both brain growth, as reflected by head circumference, and the I.Q. of the undernourished group were significantly lower than in the control group; and there was no improvement during the period of up to seven years during which they were followed.

We wish to thank Dr. E. Botha for help and advice; Dr. I. Robertson for making available clinical material; Professor F. J. Ford for facilities and help with the paper; Dr. J. G. Burger, Medical Superintendent of Groote Schuur Hospital and Dr. J. F. W. Mostert, Medical Superintendent of the Red Cross War Memorial Children's Hospital for permission to publish; Mr. A. G. Story for help with the paper and Miss C. Freese- man for the graphs; Mrs. O. M. Cartwright for the typing and Mrs. J. S. Adams for collecting the children and parents.

\section{REFERENCES}

Bayley, N. and Jones, H. E. (1937). Environmental correlates of mental and motor development: a cumulative study from infancy to six years. Child Develop., 8, 329.

Blanton, $S$. (1919). Mental and nervous changes in the children of the Volksschulen of Trier, Germany, caused by malnutrition. Ment. Hyg. (N.Y.), 3, 343.

Botha, E. (1952). Unpublished M.A. Thesis, University of Cape Town.

Brookes, A. J. and Vincett, L. S. (1950). Beef production experiment at Cambridge. Interim report. J. roy. agric. Soc. Engl., $111,99$.

Coppoletta, J. M. and Wolbach, S. B. (1933). Body length and organ weights of infants and children. A study of the body length and normal weights of the more important vital organs of the body between birth and twelve years of age. Amer. J. Path., 9, 55.

Cowley, J. J. and Griesel, R. D. (1959). Some effects of a low protein diet on a first filial generation of white rats. J. genet. Psychol., 95, 187.

- (1962). Pre- and post-natal effects of a low-protein diet on the behaviour of the white rat. Psychol. Africana, 9, 216.

Fick, M. L. (1939). An individual scale of general intelligence for South Africa. S. Afr. Coun. Educ. Soc. Res. Ser. 7. Pretoria.

Gesell, A. and Amatruda, C. S. (1947). Developmental Diagnosis, 2nd ed. Cassell, London.

Grover, V. M. (1952). The coloured nursery school child and the Merrill Palmer test. Proc. S. Afr. psychol. Ass., 3, 26.

Holt, L. E. and McIntosh, R. (1953). Holt Pediatrics, 12th ed. Appleton-Century-Crofts, New York.

Jackson, C. M. and Stewart, C. A. (1920). The effects of inanition in the young upon the ultimate size of the body and the various organs in the albino rat. J. exp. Zool., 30, 97.

Kugelmass, I. N., Poull, L. E. and Samuel, Ė. L. (1944). Nutritional improvement of child mentality. Amer. J. med. Sci., 208, 631.

McCance, R. A. (1962). Food, growth, and time. Lancet, 2, 621.

McNemar, Q. (1942). The Revision of the Stanford-Binet Scale: an Analysis of the Standardization Data. Houghton Mifflin, Boston.

Paton, D. N. and Findlay, L. (1926). Child life investigations: Poverty, nutrition and growth; studies of child life in cities and rural districts of Scotland. Spec. Rep. Ser. med. Res. Coun. (Lond.), No. 101.

Raven, J.' C. (1956). Coloured Progressive Matrices. Sets A, $A B, B$ (Revised Order 1956). Standard Scale, with Instructions, Key and Norms. H. K. Lewis, London.

Robertson, I. (1961). Weight charts of Coloured infants and preschool children. S. Afr. med. J., 35, 466.

Smythe, P. M. and Bouchier, I. A. D. (1960). Cortical atrophy of the brain in infants associated with failure to thrive. Arch. Dis. the brain in infants

Stutsman, R. (1948). Use of Merrill-Palmer Test. World Book Co., Yonkers-on-Hudson, New York.

Tredgold, R. F. (1950). A Text Book of Mental Deficiency. Baillière, Tindall and Cox, London.

Wellman, B. L. (1945). IQ changes of preschool and nonpreschool groups during the preschool years: a summary of the literature. Jroups Psychol., 20, 347.
. 